\title{
WeChat-Based Intelligent Exhibition Service Function Module Design
}

\author{
Xianping Xie ${ }^{1}$ Wanci Huang ${ }^{2}$ Jiankang Zhang ${ }^{3 *}$ \\ 1,3 School of International Economy \& Tourism Management, Zhejiang International Studies University, Hangzhou, \\ Zhejiang 310023, China \\ ${ }^{2}$ School of English Studies, Zhejiang International Studies University, Hangzhou, Zhejiang 310023, China \\ *Corresponding author. Email: zhangjk@zisu.edu.cn
}

\begin{abstract}
WeChat is favored in intelligent exhibition design because of its broad user base. WeChat is used as the carrier to carry out intelligent exhibition service module, providing one-stop exhibition service function, and assisting exhibition enterprises to upgrade data+ service wisdom. WeChat-based intelligent exhibition function service module includes exhibition guide, exhibitor products, supporting activities, business travel services, exhibitor introduction, exhibition information and so on. This function module can help the exhibition organizations to better organize and manage the exhibition, and help customers to better understand the exhibition information and participate in related activities.
\end{abstract}

Keywords: WeChat, intelligent exhibition, service function module

\section{INTRODUCTION}

WeChat has become an indispensable part of people's daily life and WeChat is favored in intelligent exhibition design because of its broad user base. The WeChat-based intelligent exhibition service function module can integrate the exhibition resource of exhibition organizers, exhibitors spectators and servicers and can provide the exhibition tour, the exhibition information, notes of exhibition, conference activities, exhibitors introduction, and the audience sign up, sign in to cancel after verification and other integrated services, meeting the personalized needs, real-time data updating exhibitors' information, function modules synchronization information automatically, solving the problem of the exhibition island of information, finally promoting more exhibition to hold smoothly. Its functional modules should include exhibition guide, exhibitor products, exhibitor introduction, exhibition information, supporting activities, business travel services and so on.

\section{EXHIBITION GUIDE}

The WeChat-based intelligent exhibition service function of exhibition guide module serves to guide exhibitors and participants to visit the exhibition, explain and guide them, in order to maximize the role of the exhibition and improve the satisfaction of exhibitors. The specific classification of exhibition guide is as follows:

\section{1. Information Guide System}

In order to make the most of the role of exhibition guide, the distribution of exhibition halls and the specific contents of the exhibition are the carriers of the information guide. Most of these guides are located at the entrance of the exhibition and have various forms of expression. The characteristics of the information guide system are the use of distinct colors, using different colors to represent different modules; special symbols, with a unique meaning to mark all kinds of exhibition stands; different amount, with different densities to show the interest degree [1].

\section{2. Navigation Guide System}

The navigation guide system is often found in large exhibitions. The exhibition hall of large-scale exhibition covers a large area and has a complex internal structure. In order to guide the visitors to the exhibition more clearly, the signs are mainly located at the entrance and exit of the exhibition hall and in areas with high population density. The main purpose is to tell people exactly the location of the destination and the route. The design features are simple and clear and can guide people accurately and quickly to the destination, less wasted road, avoid spending too much time on the way.

\section{3. Identification Guide System}

The identification board is an important judging tool, which is mainly used to help users determine where they 
are in the exhibition and allow people to find their own position immediately. This type of guide is mainly located at the top of the booth, on both sides and so on. Designers use the most attractive text or pattern, such as the name of the company, to stick in the exhibition. The system has the characteristics of innovation, integration, simplicity and focus. Through innovation, it guides people to learn new things in the drive of curiosity. Integration is the organic combination of lighting, color and products in the exhibition venue to better reflect the brand image of the exhibition. Simplicity refers to the design of the booth to make the exhibits simple and clear. Focus means to focus a booth on the main items on display. The main purpose of the system is to attract customers to understand the main products and to promote the completion of orders with product advantages. Not only that, the booth is also supposed to be conducive to sales personnel and customer communication and to promote the completion of orders.

\section{4. Intelligent Guide System}

On the basis of WeChat, the intelligent guide system further utilizes modern advanced science and technology to integrate the traditional navigation methods into one, which is convenient for tourists to self-tour. The navigation system still has the functions of guidance, explanation and instruction [2]. At present, there are two kinds of intelligent navigation systems that have been popularized, one is based on GPS, the other is based on RFID technology. Although their promotion greatly facilitates the customer to see the exhibition, it also has some defects. For example, the system cannot run smoothly where the signal is weak. In order to solve this problem, an indoor intelligent guide system based on UWB (Ultra Wideband) technology and wi-fi technology was created, which can well reduce the impact of the system failure due to external reasons. From this point of view, the indoor intelligent guide system based on UWB technology and wi-fi technology can replace the traditional navigation system in the near future.

\section{EXHIBITIONS PRODUCTS}

Give a comprehensive introduction to the products on display, focusing on the aspects of the products that most attract customers. Generally speaking, the first interface does not introduce all aspects of the product, but lists prominent features and product advantages, such as good quality and high sales. Other relevant aspects will be introduced in the following pages. The products of the exhibitors can be divided into main products, innovative products and mass products.

\section{1. Main Product}

Exhibition products should include the company's core flagship product and the company should take out the best quality products and show audience their companies' elegant demeanor. Of course, it doesn't mean that other products on display can cut corners.

\section{2. Innovative Product}

Most of the exhibits are newly developed products of the company and their performance and appearance should be first-class to show the audience the company's strong innovation and research and development capabilities.

\section{3. Mass Product}

Aimed at the consumer habits of the masses, the product is launched with a double-level guarantee of price and quality. When this kind of product is exhibited on the exhibition, consumers can truly feel the product, and can try on the spot even to be conquered by its quality and price, and achieve emotional resonance with most consumers, so as to occupy the broad consumer market.

Exhibition has a powerful product display function. Enterprises through high-tech means, such as sound, light, electricity, elaborate design platform to enhance its image, along with all kinds of propaganda, public relations and promotion activities, the concept of the enterprise and brand image can get the most effective propaganda, making customers in the shortest time to understand the characteristics of the product of the enterprise, so as to develop efficient trade negotiation and business cooperation. Exhibitors' products display which based on WeChat intelligent exhibition is a supplement to the product display function of physical exhibition, which can introduce all the information of product specifications, styles and colors in a new way.

Exhibitors' products display which based on WeChat intelligent exhibition can also improve the corporate image. Corporate image refers to the general impression of an enterprise created by people's perception of various symbols of the enterprise. It is the general impression felt by the public during their contact with the enterprise. Keller, a famous brand expert, defines corporate image as: consumers' perception of the organization is reflected by association in memory. In the process of product display, the enterprise can highlight the product quality, performance, price, product design, appearance, name, trademark and packaging image and can also display the service attitude, professional ethics, enterprising spirit and other corporate culture. 


\section{SUPPORTING ACTIVITIES}

The purpose of setting up the supporting activities function module of intelligent exhibition based on WeChat is to provide a platform for spreading information for the upcoming supporting activities, improving the attention of exhibition participants to supporting activities, and expanding the influence of supporting activities, so as to achieve the expected effect of supporting activities. These supporting activities may be sponsored by the exhibition organization, or by exhibitors or other relevant organizations. The directory of related modules lists information about the supporting activities should to be held, either by time or by place. Supporting activities mainly include: forums, awards, competitions, performances and so on.

\section{1. Forums}

Forum is the most common supporting activity during the exhibition. Modern exhibitions pay more and more attention to both exhibition and forum. During the exhibition period, exhibition organizations often organize various forums related to the exhibition theme and invite some famous scholars, experts, enterprises and government officials to participate. Holding various forums can exchange the latest information and trends in the industry, disseminate new technologies, introduce new projects, and promote new ideas and new thinking pattern in the development of the industry. The forum is a beneficial link to help the exhibition to strengthen information exchange, enhance friendship and build a bridge, which plays an important role in promoting the level of the exhibition, enhancing the quality of the exhibition and expanding the influence of the exhibition. In order to better assist the exhibition participants to participate in forum, WeChat-based intelligent exhibition supporting activities function module should divide the category of the forum, such as academic communication oriented professional seminar, technical exchanges and technical cooperation oriented technical seminars, releasing new products oriented product launch, promoting the new product oriented product promotion and so on.

\section{2. Awards}

During the exhibition, a large number of visitors bring a large number of people to gather together and the exhibition makes the relevant enterprises of a certain industry gather together. There are many favorable conditions for holding award activities during this period, and it will also have a greater impact on the industry and the society. Through evaluation and comparison, rewards for excellent performance can make the industry pioneers in a prominent position, gain the attention of the industry and the society, and thus improve the marketing effect and communication effect, which is also helpful for activating the atmosphere of the venue and attracting potential audience. The WeChat-based intelligent exhibition supporting activity function module should timely announce the organization procedure of the award evaluation activities, including the rules of the evaluation committee, the formulation and release of the activity plan, the launching of the award evaluation personnel, the composition and selection of the award committee, the media and time of the award evaluation results.

\section{3. Competition}

The competition refers to the competition in which the organizer allows the participants to compete separately or comprehensively in terms of professional technology, professional skills and intellectual capacity according to specific rules in the process of holding the exhibition, and finally evaluates the winner or the ranking according to the rules, with the purpose of promoting the development and progress of technical skills in the industry through competition [3].

The WeChat-based intelligent exhibition supporting activity function module should promote the organization of the competition, which mainly includes the formulation of the work system, the formulation of the work process, the establishment of the organization, and the allocation of human resources management. The control mainly includes cost control, schedule control, quality control and so on. The implementation of the competition, in essence, is the planning, organization and control of the three functions in the competition management, marketing management, logistics support management, risk management and other work areas of the process.

\section{4. Performance}

During the exhibition, holding various performances related to the exhibition theme is also a very common supporting activities of the exhibition. The performance activities held during the exhibition can be divided into three categories. First, literary performance. Such performances are basically held to enliven the atmosphere and expand the influence of the exhibition. For example, at the opening or closing dinner, some exhibitions will plan to hold some artistic performances to add to the fun, and some exhibitions will also specially organize a variety show attended by famous singers or movie stars during the exhibition period. Second, marketing performance activities. This kind of performance activity is to help the product marketing and promote the corporate image and held by the exhibitors mainly. For example, at an exhibition such as an auto show, many exhibitors will set up performance venues in their booths and hold performance events regularly. Third, procedural performance activities. Many of these performances are held in accordance with industry practices and industry procedures[4]. For example, many exhibition 
organizations will hold some large or small performance activities at the opening of the exhibition. The WeChatbased intelligent exhibition supporting activity function module should disseminate the performance information in time and publicize the security management during the performance [5].

\section{BUSINESS TRAVEL SERVICE}

WeChat-based intelligent exhibition business travel service mainly serves the needs of exhibition participants who want to go to some areas where the industry or market is concentrated to have an in-depth understanding of commodity information and market conditions, or to the local famous scenic areas to relax moderately. WeChatbased intelligent exhibition business travel services mainly include business investigation and sightseeing leisure.

\section{1. Business Investigation}

The so-called business investigation is to collect information about the commodity market, understand the market for the main purpose of business activities. Exhibitors and buyers have different priorities for trade, display, information and release. If exhibitors and buyers feel that what he or she has acquired at the fair has not met the full purpose of attending the fair, he or she may wish to visit the market for himself or herself [6]. Therefore, the service demand of business investigation based on WeChat intelligent exhibition emerges. The main purpose of the business visit is to collect market information and understand the market situation. The main business destinations of WeChat-based intelligent exhibition are generally designed as follows: specialized commodity market or large shopping mall; the place where a commodity is produced or where certain enterprises are located. The former is mainly to collect information related to the market, such as the selling price of commodities, to understand the design and fashion of commodities, and to study the needs of consumers. The latter is mainly to further understand the strength of the enterprise and to understand the production technology and production scale and other industry-related information [7].

\section{2. Sightseeing Leisure}

MICE tourism whose main purpose is for sightseeing and leisure is mainly after the end of the exhibition, which is relatively rare before the opening of the exhibition and during the exhibition. The purpose of this kind of MICWE tourism is to relax and broaden our knowledge while visiting scenic spots, cultural relics and other tourist attractions. In large international exhibitions, many exhibitors and buyers come from different countries and regions overseas. They may have some understanding of the market of the place where the exhibition is held but they do not have personal experience. The WeChat-based intelligent exhibition sightseeing leisure will design the main destination as the location of scenic spots and historic sites. WeChat-based intelligent exhibition sightseeing leisure in the planning of travel routes, special attention should be paid to understand the needs of customers. Otherwise, the effect will be counterproductive and leave customers a bad impression of the exhibition service.

\section{CONCLUSION}

The WeChat-based intelligent exhibition service function module provides an information, exchange and interaction platform for organizers and participants. As a rapidly developing industry, exhibition industry has unlimited development space and has become an important part of urban economy. Chinese exhibition enterprises are and should deepen and innovate in the aspects of exhibition holding, service experience and theme design, integrate WeChat into the information management of exhibition, and widely use WeChat-based intelligent exhibition service function module, so as to further meet the development needs of new exhibition forms and better improve the experience of exhibition participants.

\section{REFERENCES}

[1]Zheng, L. J, Guo, H. C. , Research on the Application of WeChat in Exhibition Management and Service. Special Zone Economics, 2017(05), pp. 80-81.

[2]Li, R. Q. , New Mode of Smart Venue: WeChat + Exhibition. Shanghai informatization, 2016(05), pp. 4042.

[3]Guo, X. Y. , Exhibition Service Alliance Mode -New Media Application Based on WeChat Public Platform . Modernization of Market, 2015(05), pp. 5253.

[4]Wang, Y, Zhao, Y. S. , Design of Large and Medium-sized Exhibition Guide with iBeacon Technology . China new Communication, 2018(10), pp. 81-84.

[5]Zhang, X. D, Han, L. Q, Wang, L. J. , Design of Intelligent Scenic Spot Navigation System Based on Spatiotemporal Information Cloud Platform. Mine Measurement, 2018(10), pp. 81-84.

[6]Kong, L. A, Wu, X. , Mobile Augmented Reality System for Campus Navigation Based on Road Sign Recognition . Information Technology, 03:116-120.

[7]Wang, S. , Beyond the Site: New Media Micro Communication of Exhibition Projects -- Taking the Operation of WeChat Public Account of 11 Exhibition Projects as an Example. Today's Media, 2019(01), pp. 77-80. 